\title{
Beggar thy thrifty neighbour \\ The international spillover effects of pensions under population ageing
}

\author{
Yvonne Adema • Lex Meijdam • Harrie A. A. Verbon
}

Received: 21 April 2006 / Accepted: 2 March 2007 /

Published online: 25 May 2007

(C) Springer-Verlag 2007

\begin{abstract}
This paper explores the international spillover effects of ageing through capital markets when countries have different pension systems. We use a two-country two-period overlapping-generations model, where the two countries only differ in their pension schemes. Two forms of population ageing are considered, namely, an increase in longevity and a fall in fertility. It is shown that, in the long run, a country using a funded pension system experiences negative spillovers from the fact that the other country uses a pay-as-you-go system. The short-run spillovers, however, are opposite to the spillovers in the long run.
\end{abstract}

Keywords Ageing $\cdot$ Pensions $\cdot$ Spillovers

JEL Classification $\mathrm{F} 21 \cdot \mathrm{H} 55 \cdot \mathrm{J} 11$

\section{Introduction}

In the coming decades, differences in the extent and the timing of ageing in the developed world will lead to international spillover effects through the capital

Responsible editor: Junsen Zhang

Y. Adema $(\varangle) \cdot$ L. Meijdam

Department of Economics, CentER, and Netspar, Tilburg University,

P.O. Box 90153, 5000 LE Tilburg, The Netherlands

e-mail: y.adema@uvt.nl

L. Meijdam

e-mail: a.c.meijdam@uvt.nl

H. A. A. Verbon

Department of Economics, CentER, Netspar, and CESifo, Tilburg University,

P.O. Box 90153, 5000 LE Tilburg, The Netherlands

e-mail: h.a.a.verbon@uvt.nl 
market. This has been established in an extensive literature, starting with a seminal paper by Cutler et al. (1990), followed by a number of papers presenting simulation experiments with large multi-country overlapping-generations models (see, for example, Brooks 2003; Fehr et al. 2005; Börsch-Supan et al. 2006; Domeij and Flodén 2006; Attanasio et al. 2006).

Less attention, however, has been paid to a second possible reason for international spillover effects in case of ageing, i.e. differences in pension systems between countries. Within the European Economic and Monetary Union (EMU), for example, there are large differences in pension arrangements. Some countries, such as The Netherlands, have large funded schemes, whereas other countries, e.g. Italy and Germany, rely almost completely on pay-as-you-go (PAYG) systems. Together with differences in the institutional set-up of PAYG schemes, this causes savings in the various countries to react differently to the ageing of the population, even if the pattern of ageing is identical across countries. In a common capital market, these differences in savings will spill over to other countries.

The aim of this paper is to explore the international spillover effects of a symmetric ageing shock when countries in a common capital market have different pension systems. In other words, we want to shed light on the question how, in case of population ageing, a country with an extensive funded pension scheme (e.g. The Netherlands) is affected by the fact that other EMU countries (such as Italy) rely to a relatively large extent on unfunded pensions, and vice versa.

Some studies (for example, Casarico 2001; Groezen 2003; Jousten and Legros 2002) investigate what happens with capital flows when two countries that differ in the degree of funding of their pension systems integrate their capital markets. Casarico (2001) finds that the young and the future generations in the PAYG country are better off in the open economy equilibrium. In the funded country, however, welfare can either increase or decrease for the young and future generations. So, it is not necessarily true, as one might expect, that both countries gain from the integration of capital markets. In contrast to the aforementioned papers, we study the consequences of ageing given that countries have an integrated capital market but different pension arrangements. To our knowledge, our paper is one of the first taking this approach. One exception is the paper by Börsch-Supan et al. (2006) who also allow for differences in the generosity of public PAYG pension schemes. In contrast to that paper, we develop a simple model that enables us to derive an analytical solution of the transition path, to gain insight into the underlying mechanisms of the results.

We use a two-country two-period overlapping-generations model where one country has a PAYG pension system and the other country has a fully funded retirement scheme. The countries are identical in all other respects and are hit by an identical demographic shock. Two typical variants of the PAYG scheme are distinguished: a defined-benefit scheme where the working generation bears the burden of an ageing population by paying higher taxes, and a fixed-contribution scheme where the burden of ageing lies with the elderly. Moreover, we consider two forms of population ageing, namely, an increase in longevity and a decrease in fertility.

We find that, in general, a country with funded pensions is, in the long run, adversely affected by the existence of a PAYG scheme in the other country. This means that a country using a funded system is more vulnerable to an ageing shock 
when it has a common capital market with a country relying on PAYG pensions. In the short-run, however, the spillover effects may be opposite: Generations born in the country with the funded pension scheme around the time of the demographic shock may gain from the fact that the other country has a PAYG scheme. The reason for this is that the rise in the capital-labour ratio, resulting from the ageing shock, is smaller in case the funded country has integrated capital markets with a country that uses a PAYG pension scheme instead of a funded system. As a result, the fall in the interest rate, which especially harms these initial generations, is less.

The rest of the paper is organised as follows. Section 2 presents the benchmark model. In Section 3, we discuss the spillover effects when ageing is modelled as an increase in longevity, first in case of a defined-benefit PAYG scheme and then shortly for the case of fixed contributions. Section 4 deals with modifications of the model. We analyse the spillover effects with a decline in fertility instead of an increase in longevity (Section 4.1) and with a more general type of utility function (Section 4.2). Moreover, we discuss how the results would change in case of anticipated and asymmetric shocks (Section 4.3). The final section concludes.

\section{The model}

Following Buiter (1981), we use a two-period overlapping-generations model of an open economy. The world consists of two countries, country $P$ and country $F$, and the only difference between the two countries is the way the pensions are financed. Country $P$ uses a PAYG system, and country $F$ has a fully funded retirement scheme.

\subsection{Demographics}

Both economies are populated with non-altruistic, identical individuals who live for at most two periods. So, in each period, both a young and an old generation are alive. We assume that an agent born at $t$ lives throughout old age with probability $\varepsilon_{t+1} \cdot \varepsilon_{t}$ can be interpreted as average longevity; when $\varepsilon_{t}$ rises, the expected lifespan of people is longer.

The active population, $L_{t}^{i}$, is supposed to increase at the same exogenous rate $n_{t}{ }^{1}$ The number of active (young) people at time $t$ is then:

$$
L_{t}^{i}=L_{0}^{i} \cdot \prod_{j=0}^{t}\left(1+n_{j}\right)
$$

where $L_{0}^{i}$ is the initial population size in country $i, i=P, F$. A decrease in $n_{t}$ can be interpreted as a fall in the fertility rate. As the countries may differ in their initial population size, the model allows for scale differences between the two countries. Define $\frac{L_{0}^{F}}{L_{0}^{P}}=v$; so, if $L_{0}^{P}$ is normalised to 1 , then $v$ tells us the relative size of $L_{0}^{F}$.

\footnotetext{
${ }^{1}$ Throughout this paper, both economies are assumed to be dynamically efficient, i.e. $r_{t}>n_{t}, \forall t$.
} 


\subsection{Production}

All variables in the model are expressed as the amount per young individual in the country. For example, $k_{t}^{i}$ stands for the amount of capital per young individual in period $t$ in country $i$. Production per young individual is described by a standard neoclassical constant-returns-to-scale production function, $f\left(k_{t}^{i}\right)$. Perfect competition among producers results in the usual equilibrium conditions, $r_{t}^{i}=f^{\prime}\left(k_{t}^{i}\right)-\delta$ and $w_{t}^{i}=f\left(k_{t}^{i}\right)-k_{t}^{i} f^{\prime}\left(k_{t}^{i}\right)$, where $r_{t}^{i}$ is the interest rate, $w_{t}^{i}$ denotes the real wage and $\delta$ is the depreciation rate of capital. There is perfect capital mobility between the two countries, but labour is immobile. Because capital can freely move across countries, the interest rates will be equalised, i.e. $r_{t}^{P}=r_{t}^{F}=r_{t}, \forall t$. As both countries are endowed with the same production technology, we have $k_{t}^{P}=k_{t}^{F}=k_{t}$, and consequently $w_{t}^{P}=w_{t}^{F}=w_{t}$.

\subsection{Government}

The government in country $P$ runs a PAYG pension system, that is, the pension benefits of the elderly $\left(z_{t}^{P}\right)$ are covered by lump-sum ${ }^{2}$ taxes of the young $\left(\tau_{t}^{P}\right)$. Because, at time $t$, there are $\varepsilon_{t} L_{t-1}^{P}$ old agents and $L_{t}^{P}$ young agents, a PAYG system satisfies:

$$
z_{t}^{P}=\frac{1+n_{t}}{\varepsilon_{t}} \tau_{t}^{P}
$$

In country $F$, the government invests the contributions of the young $\left(\tau_{t}^{F}\right)$ and returns them with interest in the next period in the form of transfers to the then old agents $\left(z_{t+1}^{F}\right)$. As only a fraction of $\varepsilon_{t+1}$ of young people born at $t$ survives to period $t+1$, the contributions of those who deceased will fall to surviving contemporaries. In this case, we have:

$$
z_{t+1}^{F}=\frac{1+r_{t+1}}{\varepsilon_{t+1}} \tau_{t}^{F}
$$

\subsection{Households}

Expected lifetime utility of a representative individual born at $t$ is given by the following utility function:

$$
E_{t} U\left(c_{t}^{y, i}, c_{t+1}^{o, i}\right)=\log \left(c_{t}^{y, i}\right)+\frac{1}{1+\rho} \varepsilon_{t+1} \log \left(c_{t+1}^{o, i}\right)
$$

where $\rho>0$ stands for the (constant) pure rate of time preference of an individual, $c_{t}^{y, i}$ is consumption when young and $c_{t+1}^{o, i}$ is consumption in the second period of life.

Young agents inelastically supply one unit of labour. Introducing endogenous labour supply instead would complicate our analysis to a large extent, as this leads us into questions like how labour supply enters the utility function. Moreover, empirical

\footnotetext{
${ }^{2}$ Assuming proportional taxes, instead of lump-sum taxes, would lead to smaller effects, as an increase in wages, after ageing, will dampen the effect on taxes. Qualitatively, our results will not change however.
} 
studies find that the labour supply elasticity is fairly small for the principal earner of a household; see Blundell and MaCurdy (1999) for an overview. We assume perfect annuity markets, ${ }^{3}$ which implies that the assets of those who deceased are distributed among the people who survived. The total return on savings is, therefore, $\frac{1+r_{t+1}}{\varepsilon_{t+1}}$. The consolidated lifetime budget constraint is:

$$
c_{t}^{y, i}+\frac{\varepsilon_{t+1} c_{t+1}^{o, i}}{1+r_{t+1}}=w_{t}-\tau_{t}^{i}+\frac{\varepsilon_{t+1} z_{t+1}^{i}}{1+r_{t+1}}
$$

Maximising lifetime utility with respect to the lifetime budget constraint gives the following expressions for individual optimal savings in both countries:

$$
\begin{gathered}
s_{t}^{P}=\frac{\varepsilon_{t+1}}{1+\rho+\varepsilon_{t+1}}\left[w_{t}-\tau_{t}^{P}\right]-\frac{1+\rho}{1+\rho+\varepsilon_{t+1}} \frac{\varepsilon_{t+1} z_{t+1}^{P}}{1+r_{t+1}} \\
s_{t}^{F}+\tau_{t}^{F}=\frac{\varepsilon_{t+1}}{1+\rho+\varepsilon_{t+1}} w_{t}
\end{gathered}
$$

Note that optimal savings in country $F$ do not depend on the interest rate. The reason is that, given a logarithmic utility function, the intertemporal substitution elasticity is equal to one. For the same reason, optimal savings in country $P$ only react to the interest rate because it changes the net present value of the pension benefit.

\subsection{Equilibrium international capital market}

Individuals invest their savings either in the home country or abroad. Their portfolios will be composed such that interest rates are equalised. Equilibrium in the international capital market is given by:

$$
s_{t}^{P}+v\left(s_{t}^{F}+\tau_{t}^{F}\right)=(1+v)\left(1+n_{t+1}\right) k_{t+1}
$$

From Eqs. 6 and 7, it can be seen that country $F$ has higher savings than country $P$, implying that country $F$ exports capital abroad.

\section{Increase in longevity}

One of the causes of population ageing is that people live longer. Therefore, in this section, we analyse the international spillover effects when longevity increases permanently at $t=0$. The demographic shock is unexpected, i.e. people do not adjust their behaviour in the period before the shock. Moreover, the size and the timing of the ageing shock is the same in both countries. As a result, ageing will induce capital flows between the two countries only because the pension systems differ.

\footnotetext{
${ }^{3}$ Relaxing this assumption would probably only reinforce our results, as in the absence of a perfect annuity market, households in the funded country will have a stronger incentive to save for old age. As a result, capital flows from the funded to the unfunded country, which drive most of our results, will only be larger.
} 
We employ the method of comparative dynamics, adopted from Judd (1982), to calculate the effect of the longevity shock analytically. The probability of reaching the second period of life at time $t$ is given by:

$$
\varepsilon_{t}=\varepsilon+\pi h_{t}
$$

where $\varepsilon$ denotes the initial steady-state value, ${ }^{4} h_{t}$ describes the time pattern of a perturbation of this steady-state value and $\pi$ reflects the magnitude of this perturbation. Ageing is reflected by a positive value of $h_{t}{ }^{5}$ To focus solely on the effects of an increase in longevity, we assume that there is no population growth, i.e. $n_{t} \equiv 0 \forall t$. The effects of an ageing shock can be traced by linearising the capital-accumulation Eq. 8 with respect to $\pi$ around the initial steady state. The resulting first-order difference equation for $k_{t}$ describes the capital-labour ratio changes over time and the determining factors. Given the change in the capital-labour ratio, we can derive the changes in all other variables.

First, we explain the effects of an increase in longevity when the PAYG system is characterised by defined benefits. After that, we shortly describe what changes when the PAYG system is characterised by fixed contributions instead.

\subsection{Defined benefits}

This section analyses the international spillover effects of population ageing in case the PAYG scheme is characterised by defined benefits. In terms of the model, this means that the pension benefit in country $P$ is fixed at $z^{P}\left(z_{t}^{P}=z^{P} \forall t\right)$. This implies that, in response to a longer expected lifespan, taxes have to increase to keep the PAYG scheme balanced. So, the burden of ageing is entirely borne by the working population.

\subsubsection{The change in the capital-labour ratio}

Using the method described above, we obtain the following first-order difference equation for the evolution of the capital-labour ratio: ${ }^{6}$

$$
\begin{aligned}
\frac{\partial k_{t+1}^{F P}}{\partial \pi}= & -\frac{\varepsilon f^{\prime \prime}(k) k}{\Psi} \frac{\partial k_{t}^{F P}}{\partial \pi}-\overbrace{\frac{z^{P} \varepsilon}{(1+v) \Psi}}^{3} h_{t} \\
& +[\overbrace{\frac{(1+\rho)\left(w-\frac{\tau^{P}}{1+v}\right)}{\Psi(1+\rho+\varepsilon)}-\overbrace{\frac{(1+\rho)^{2} z^{P}}{(1+v) \Psi(1+\rho+\varepsilon)(1+r)}}^{1+\rho+\rho}] h_{t+1}}^{\frac{1}{(1+\rho)}}]
\end{aligned}
$$

where $\Psi \equiv(1+\rho+\varepsilon)-\frac{(1+\rho) \varepsilon z^{P} f^{\prime \prime}(k)}{(1+v)(1+r)^{2}}>0$.

\footnotetext{
${ }^{4}$ Throughout the paper, we omit time subscripts to denote the (initial) steady-state value of the respective variable.

${ }^{5}$ Because we assume that longevity increases permanently; this means that $h_{0}=h_{1}=\ldots=h_{\infty}>0$. However, as people do not anticipate the rise in longevity, we have that $E_{t=-1}\left(h_{0}\right)=0$.

${ }^{6}$ In Appendix 1, we show the derivation of this expression.

悬 Springer
} 
Equation 10 shows the change in the capital-labour ratio after an increase in longevity when the two economies have different pension schemes. To analyse the international spillover effects, we derive the same kind of equations for the situation where the two economies use the same pension system. The first-order difference equation for the case where both countries have a PAYG scheme is given by:

$$
\frac{\partial k_{t+1}^{P P}}{\partial \pi}=-\frac{\varepsilon f^{\prime \prime}(k) k}{\Psi^{P}} \frac{\partial k_{t}^{P P}}{\partial \pi}-\overbrace{\frac{z^{P} \varepsilon}{\Psi^{P}}}^{3} h_{t}+[\overbrace{\frac{(1+\rho)\left(w-\tau^{P}\right)}{\Psi^{P}(1+\rho+\varepsilon)}}^{1}-\overbrace{\frac{(1+\rho)^{2} z^{P}}{\Psi^{P}(1+\rho+\varepsilon)(1+r)}}^{2}] h_{t+1},
$$

whereas the expression for the change in $k_{t+1}$ in case both economies use a funded system is given by:

$$
\frac{\partial k_{t+1}^{F F}}{\partial \pi}=-\frac{\varepsilon f^{\prime \prime}(k) k}{\Psi^{F}} \frac{\partial k_{t}^{F F}}{\partial \pi}+\overbrace{\frac{(1+\rho) w}{\Psi^{F}(1+\rho+\varepsilon)}}^{1} h_{t+1}
$$

with $\Psi^{P} \equiv(1+\rho+\varepsilon)-\frac{(1+\rho) \varepsilon z^{P} f^{\prime \prime}(k)}{(1+r)^{2}}>0$ and $\Psi^{F} \equiv(1+\rho+\varepsilon)>0$.

By comparing the capital-labour ratio changes in case the two countries have the same pension system (Eqs. 11 and 12) with the change in the capital-labour ratio when the two countries have different pension schemes (Eq. 10), we derive the pure spillover effects of pensions and ageing in a common capital market. ${ }^{7,8}$

As the increase in longevity at $t=0$ is not anticipated, savings at $t=-1$ do not adjust, and as a result, the capital stock per worker does not change at the time of the shock, that is, $\frac{\partial k_{0}}{\partial \pi}=0$. At $t=0$, there are several effects that influence optimal savings in both countries in different directions. First of all, people have more incentives to save because the chance of reaching the second period of life is higher (this effect is indicated by a 1 in the first-order difference equations). In country $P$, however, the existence of PAYG pension benefits has a depressing effect on savings when longevity goes up. The reason for this effect (indicated by a 2) is that the present value of the pension benefit rises, which raises lifetime income and thus consumption in both periods of life. For a given net wage income, the increase in consumption when young implies lower savings. Moreover, with a defined-benefit PAYG pension scheme, savings decrease, as contributions have to go up to keep the PAYG system balanced (this is the so-called dependency-ratio effect, indicated by a 3 ). So, the effect on total savings, and the capital-labour ratio, is ambiguous.

\footnotetext{
${ }^{7}$ To exclude the effects of integration, it is assumed that the initial steady state is the same in all cases. ${ }^{8}$ Assuming that both countries have the same type of pension system and comparing this to the situation where each adopts a different scheme is the same as comparing the open equilibrium to the closed-economy outcome: When both countries have the same pension design and when they are subject to the same ageing shock, there are no international capital flows, and therefore, it is as if the countries were closed.
} 
Fig. 1 Change in $k_{t}$

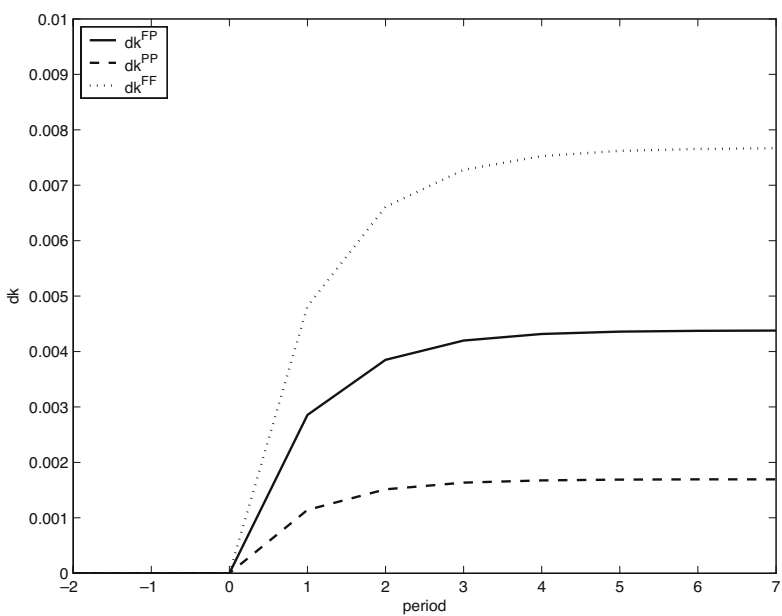

From Eq. 10, it follows that, given that $h_{t}=h_{t+1}$, the capital-labour ratio rises after a permanent increase in longevity if:

$$
\frac{z^{P}}{1+v}<\frac{(1+\rho)(1+r) w}{\varepsilon(1+\rho)(1+r)+(1+\rho)^{2}+\varepsilon(1+\rho+\varepsilon)(1+r)}
$$

We assume that this condition is fulfilled. ${ }^{9}$ The increase in the common capitallabour ratio at $t=1$ leads to higher wages, which engenders higher savings in both countries (this is the first term in the three equations). Due to these higher savings, the capital-labour ratio continues to rise.

Savings unambiguously rise more in the funded country than in the PAYG country, as effects 2 and 3 do not appear in Eq. 12. When the funded country has a common capital market with a PAYG country, part of its extra savings flows to country $P$. To illustrate the mechanics of the model, we also show some numerical simulation experiments. ${ }^{10}$ The change in the capital-labour ratio for the three different cases can be seen in Fig. 1.

\subsubsection{The change in utility}

To infer whether a country gains or loses from being in an integrated capital market with a country that has another pension system, we compare the utility effects of

\footnotetext{
${ }^{9}$ As shown in Appendix 2.1, this condition holds for realistic parameter values. The appendix also shows, however, that in case both countries have a PAYG scheme, the contribution rate does not have to be unrealistically high for the capital-labour ratio to decrease after a longevity shock. This would not change the international spillover effects qualitatively however.

${ }^{10}$ The graphs are based on simulations with $f\left(k_{t}\right)=k_{t}^{0.3}, v=1, \frac{\tau^{P}}{w}=0.2, \varepsilon=0.94$ and $h_{t}=0.05$. Capital depreciates at $5 \%$ per year, and assuming that one period is 30 years, this means that $\delta=1-$ $(0.95)^{30}=0.7854$. Agents are relatively patient with a time preference rate of $1 \%$ per year, so that $\rho=(1.01)^{30}-1=0.3478$. We also derived numerically the non-linear transition path and compared the numerical results with those found with the method of comparative dynamics. The relative error of the linearised path was $1 \%$ at most.
} 
Fig. 2 Change in $U_{t}^{P}$

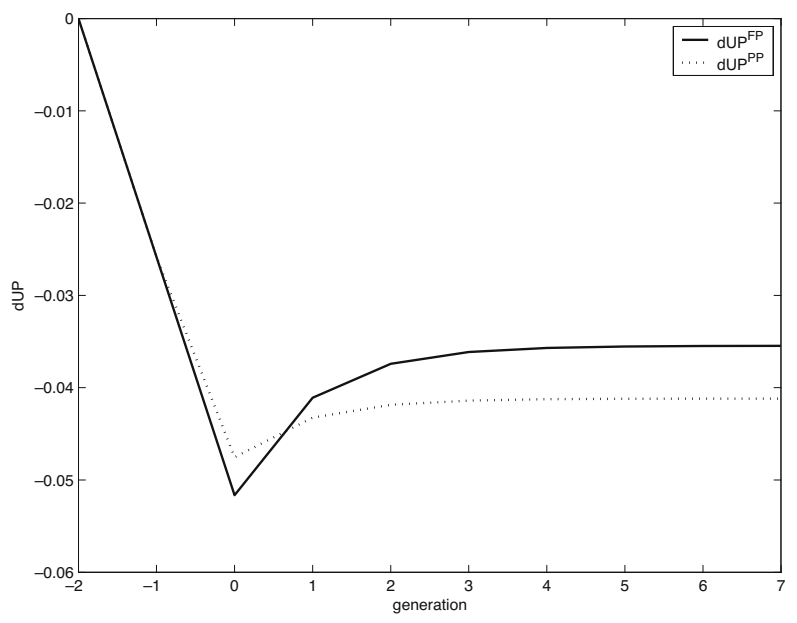

ageing in the different cases. In Appendix 3, we derive the long-run change in utility in both countries; for the PAYG country, we get:

$$
\frac{\partial U_{\infty}^{P}}{\partial \varepsilon_{\infty}}=\frac{f^{\prime \prime}(k)}{c^{y, P}(1+r)}\left[s^{P}-k(1+r)\right] \frac{\partial k_{\infty}}{\partial \varepsilon_{\infty}}-\frac{1}{c^{y, P}}\left(z^{P}+\frac{s^{P}}{\varepsilon}\right)
$$

The last term indicates that, for a given production capacity, an increase in longevity leads to a lower utility, as individuals have to share total lifetime consumption with more people. ${ }^{11}$ As explained in the appendix, the whole term in front of $\frac{\partial k_{\infty}}{\partial \varepsilon_{\infty}}$ is positive. This means that the rise in the capital-labour ratio after an increase in longevity reduces the direct negative utility effects. However, this indirect positive effect on utility is a second-order effect and, therefore, not large enough to compensate for the negative utility effects, as can also be seen in Fig. 2.

The rise in the capital-labour ratio is larger in case the PAYG country is in a common capital market with a funded country instead of with a PAYG country. As a result, in the long run, the PAYG country gains from having a common capital market with a country that has a fully funded pension scheme. Notice, however, that the spillovers are exactly opposite for the generation born at the time of the ageing shock $(t=0)$. The reason for this is that the fall in the interest rate resulting from the rise in the capital-labour ratio, which especially harms this initial generation, is less in case both countries use a PAYG system. As these initial generations do not enjoy the gains that result from a larger increase in wages when the economies have different pension schemes, the negative utility effects of the lower interest rate are smaller in case the PAYG country does not have a common capital market with a country using a funded pension system.

\footnotetext{
${ }^{11}$ To compare lifetime utility before and after ageing properly, we take the value of $\varepsilon_{t}$ constant at unity. So, we do not take into account that a higher life expectancy is actually something that is nice for people. If this is taken into account, the overall utility effects of an increase in longevity are still negative however. An increase in longevity only results in a higher utility if people can work longer. We leave this for future research.
} 
The change in long-run utility in the funded country is given by:

$$
\frac{\partial U_{\infty}^{F}}{\partial \varepsilon_{\infty}}=\frac{f^{\prime \prime}(k)}{c^{y, F}(1+r)}\left[\left(s^{F}+\tau^{F}\right)-k(1+r)\right] \frac{\partial k_{\infty}}{\partial \varepsilon_{\infty}}-\frac{1}{c^{y, F}} \frac{\left(s^{F}+\tau^{F}\right)}{\varepsilon}
$$

Again, there is the direct negative effect on utility because consumption has to be shared with more people. For the funded country, however, it is not necessarily true that a higher capital-labour ratio results in a higher utility. As explained in the appendix, there are two opposing mechanisms, which can make the whole expression in front of $\frac{\partial k_{\infty}}{\partial \varepsilon_{\infty}}$ either negative or positive. For realistic values of the different parameters, it is positive however. Because the capital-labour ratio increases less in case the funded country has a common capital market with a PAYG country rather than with a funded-pension country, the fall in utility in country $F$ is larger in the former case. So, the funded country experiences negative spillover effects from the PAYG country in the long run, as shown in Fig. 3.

As was the case for the PAYG country, the short-run spillovers are opposite to the spillovers in the long run. The reason is that the initial generations only incur the losses that result from a falling interest rate; they do not have the gains from the higher wages. As the fall in the interest rate is larger in case both countries use a fully funded system, these generations experience a larger utility loss. Notice that the effect of interest rate decreases has more impact in the funded country than in the PAYG country, as households save more in the funded country. As a result, it takes more generations to invert the spillover effects.

In the simulation graphs, we assumed that the two economies have the same size, that is, $v=1$. However, as most EMU countries mainly use PAYG pension schemes, a country like The Netherlands, relying to a relatively large extent on funded pensions, can be considered as relatively small. In case the funded country is smaller than the PAYG country, that is, when $v<1$, the negative spillover effects for the funded country become larger.

Fig. 3 Change in $U_{t}^{F}$

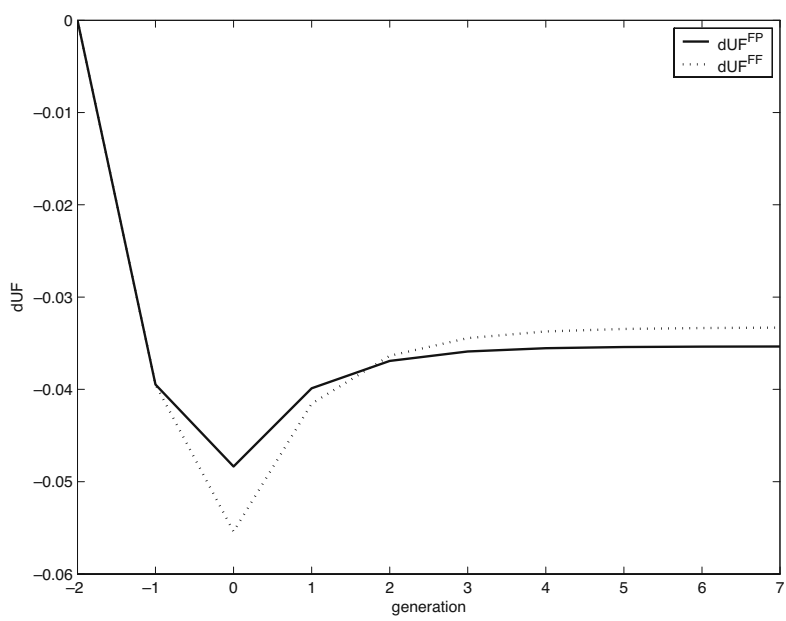




\subsection{Fixed contributions}

If the PAYG pension system is characterised by fixed contributions, the change in the capital-labour ratio, in case of different pension schemes, is described by:

$$
\begin{aligned}
\frac{\partial k_{t+1}^{F P}}{\partial \pi}= & -\frac{\varepsilon f^{\prime \prime}(k) k}{\Psi} \frac{\partial k_{t}^{F P}}{\partial \pi}+[\overbrace{\frac{(1+\rho)\left(w-\frac{\tau^{P}}{1+v}\right)}{\Psi(1+\rho+\varepsilon)}}^{1} \\
& -\overbrace{\frac{(1+\rho)^{2} z^{P}}{(1+v) \Psi(1+\rho+\varepsilon)(1+r)}}^{2}+\overbrace{\frac{(1+\rho) \tau^{P}}{(1+v) \Psi(1+r) \varepsilon}}^{3}] h_{t+1}
\end{aligned}
$$

The only difference with Eq. 10 is the dependency-ratio effect (indicated by a 3 in both equations). In case of defined benefits, the higher dependency ratio led to less savings because contributions had to rise to keep the PAYG system balanced. With a fixed PAYG tax, however, pension benefits are reduced due to a higher dependency ratio, which increases savings. This implies that the capital-labour ratio increases more in case the PAYG scheme is characterised by fixed contributions, resulting in a smaller decrease in utility after a longevity shock. However, as shown formally in Appendix 4, savings in country $F$ still increase more than in country $P$, so that the rise in the capital-labour ratio is smaller when country $F$ has integrated capital markets with a country that uses a PAYG pension system. This can also be seen in Fig. 4. In the long run, this results in positive spillover effects for the PAYG country and negative spillovers for the funded country. It should be noticed, however, that the spillovers are smaller than in the defined benefits case.

Fig. 4 Change in $k_{t}$

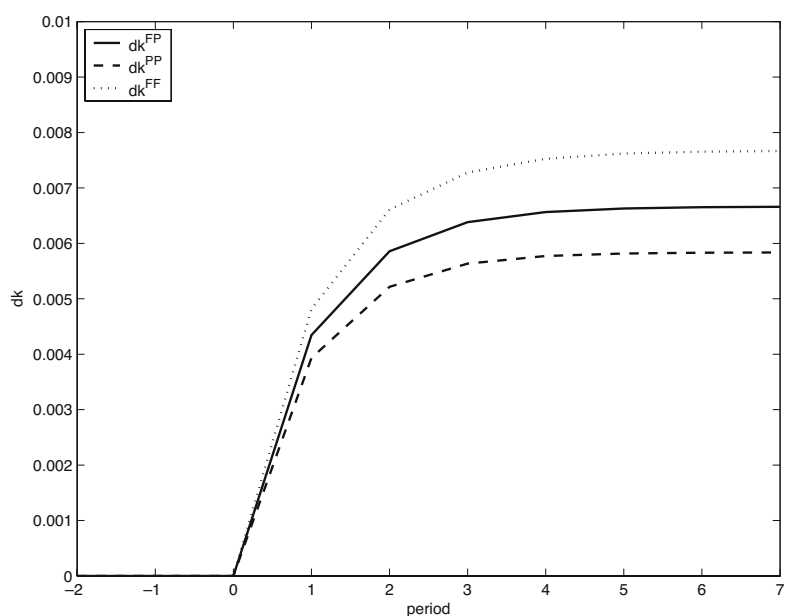


Our main findings can be summarised as follows:

Result 1. In case ageing is characterised by an unexpected increase in longevity:

1. Savings in the funded country unambiguously rise more than in the PAYG country, which leads to capital flows from the funded country to the PAYG country.

2. In the long run, the funded country experiences negative spillover effects from the PAYG scheme in the other country.

3. The short-run spillovers are opposite to the spillovers in the long run.

4. The spillovers are smaller in case the PAYG pension system is characterised by fixed contributions compared to a defined-benefit PAYG scheme.

\section{Modifications}

In this section, the analysis presented above is modified in several ways to investigate the robustness of our results. First, we study the international spillover effects in case population ageing is caused by a lower fertility rate. Second, we consider a more general type of utility function. More precisely, we analyse whether the spillover effects change when preferences are represented by a Constant Elasticity of Substitution (CES) utility function instead of a logarithmic utility function. Finally, we briefly discuss the effect of anticipated and asymmetric shocks.

\subsection{Decrease in fertility}

The ageing of the population in the industrialised world is not only caused by the fact that people live longer. Another important reason is that women give birth to a smaller number of children, that is, the fertility rate is declining. In this section, we analyse the spillover effects of pensions and population ageing in case of an unanticipated permanent decrease in fertility at $t=0$. As before, we employ the method of comparative dynamics. Let the fertility rate at time $t$ be given by $n_{t}=n+\pi g_{t}$. Ageing is reflected by a negative value of $g_{t}{ }^{12}$ To isolate the effects of a fertility decline, it is assumed that agents live throughout their old age with certainty, i.e. $\varepsilon_{t} \equiv 1 \forall t$. And again, we distinguish between a defined-benefit and a fixed-contribution PAYG scheme.

The main difference with a longevity shock is that a decline in the rate of population growth leads to a shrinking labour force, so that less investment is needed to keep the capital-labour ratio constant. This so-called capital-thickening effect has a direct positive effect on the capital-labour ratio. As a result of this capital-thickening effect, a fall in fertility can actually have positive utility effects for individuals.

\footnotetext{
${ }^{12}$ A permanent fall in fertility implies that $g_{0}=g_{1}=\ldots=g_{\infty}<0$, but as the decline in fertility is not anticipated, $E_{t=-1}\left(g_{0}\right)=0$. 
Fig. 5 Change in $k_{t}$

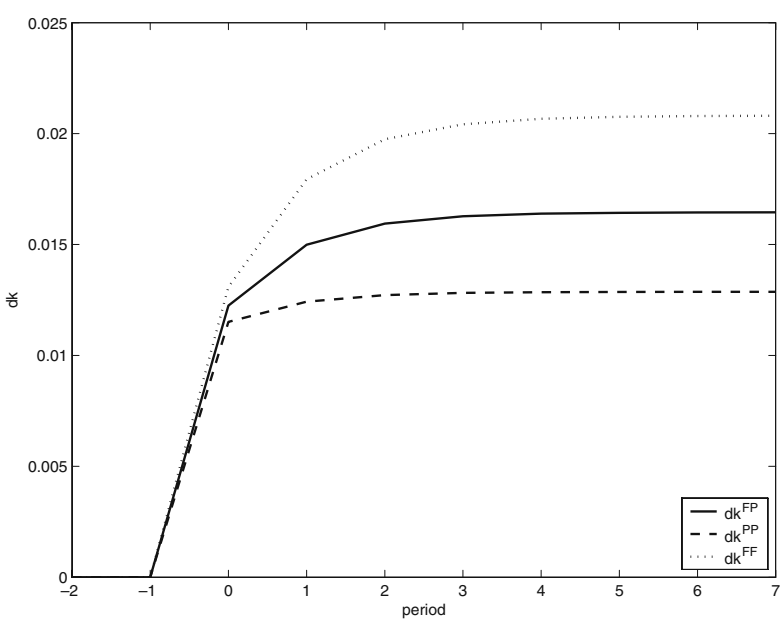

\subsubsection{Defined benefits}

The first-order difference equation for the change in the capital-labour ratio is:

$$
\frac{\partial k_{t+1}^{F P}}{\partial \pi}=-\frac{f^{\prime \prime}(k) k}{\Delta} \frac{\partial k_{t}^{F P}}{\partial \pi}+\overbrace{\frac{z^{P}}{(1+v) \Delta}}^{3} g_{t}-\overbrace{\frac{(2+\rho) k}{\Delta}}^{4} g_{t+1}
$$

with $\Delta \equiv(2+\rho)-\frac{(1+\rho) z^{P} f^{\prime \prime}(k)}{(1+v)(1+r)^{2}}>0$.

The just described capital-thickening effect is indicated by a 4 in Eq. 17. As before, the fall in fertility has a dependency-ratio effect in the PAYG country (effect 3), which affects savings negatively in case of a defined-benefit system. ${ }^{13}$ Because the country with the funded pension system does not have the negative dependency ratio effect, the capital-labour ratio increases more when this country is not integrated with country $P$. Figure 5 confirms these results. ${ }^{14}$

Figures 6 and 7 illustrate the effects of the decrease in fertility on utility in the PAYG country and the funded country, respectively. Notice that lifetime utility is higher in the funded country in the long run as compared to the initial steady state, which is due to the capital-thickening effect. In the PAYG country, however, the long-run utility effects are negative, as in our benchmark simulation the dependencyratio effect dominates the capital-thickening effect. In case the PAYG system is not too large, that is, when the dependency-ratio effect is not too large, people in country

\footnotetext{
${ }^{13}$ As in Section 3.1, we can derive a condition that has to hold for the capital-labour ratio to rise after an ageing shock. From Eq. 17, it follows that, given $g_{t}=g_{t+1}, k_{t}$ rises after a permanent decline in the fertility rate if $\frac{z^{P}}{1+v}<(2+\rho) k$. As shown in Appendix 2.2, this condition holds for a large range of parameter values.

${ }^{14}$ In these simulation graphs, it is assumed that the population size is constant in the initial steady state $(n=0)$. Assuming a positive population growth rate in the original steady state does not qualitatively change our results. We take $g_{t}=-0.1$.
} 
Fig. 6 Change in $U_{t}^{P}$

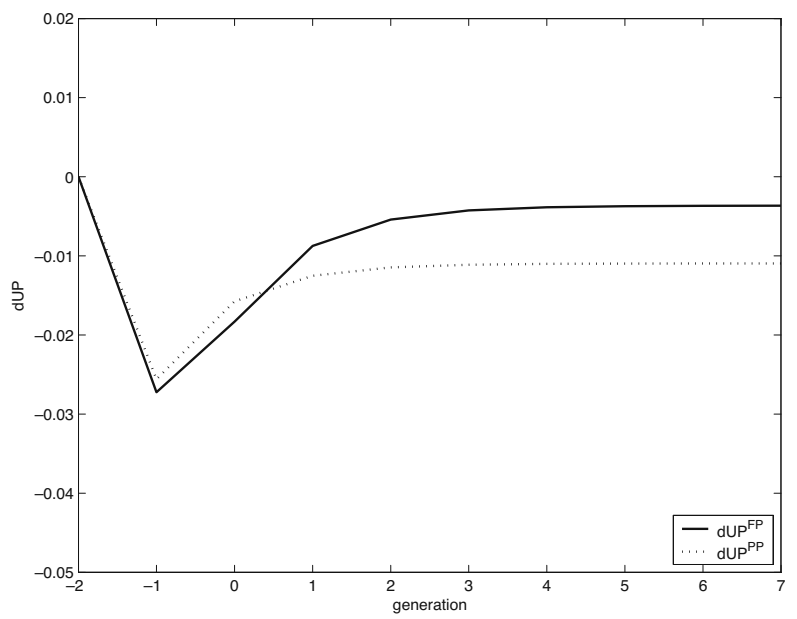

$P$ also experience positive utility effects of a fall in fertility in the long run. From simulations, it follows that this is the case if $\tau^{P}<0.13 w$.

The international spillover effects of a fertility shock can also be seen from these graphs. Figure 7 shows that, in the long run, individuals in country $F$ experience negative spillover effects from the PAYG scheme in the other country. That is, utility rises more in the long run if country $F$ has a common capital market with a country that also has funded pensions. People in the PAYG country, however, gain in the long run from having integrated capital markets with a country that uses a funded pension system (Fig. 6). In the short-run, the spillovers are opposite to the effects in the long run as was the case in Section 3.1. So, the international spillover effects do not change qualitatively compared to the effects of the longevity shock.

Fig. 7 Change in $U_{t}^{F}$

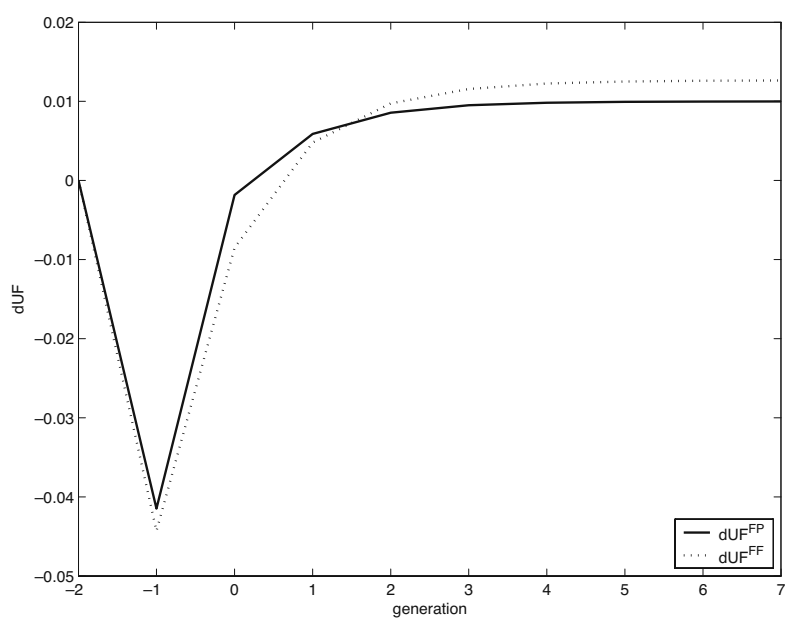


Fig. 8 Change in $k_{t}$

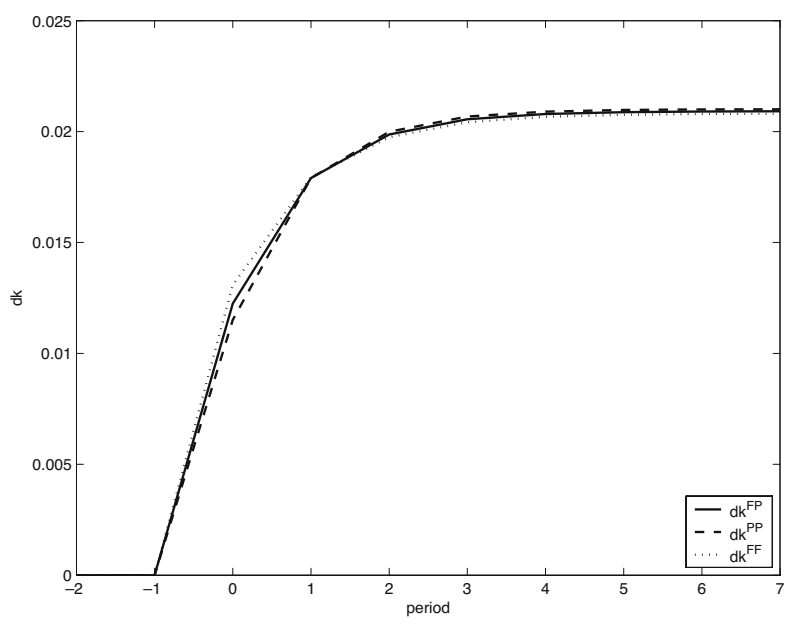

\subsubsection{Fixed contributions}

The first-order difference equation for $\frac{\partial k_{t+1}}{\partial \pi}$ in case of fixed contributions is:

$$
\frac{\partial k_{t+1}^{F P}}{\partial \pi}=-\frac{f^{\prime \prime}(k) k}{\Delta} \frac{\partial k_{t}^{F P}}{\partial \pi}-[\overbrace{\frac{(2+\rho) k}{\Delta}}^{4}+\overbrace{\frac{(1+\rho) \tau^{P}}{(1+v) \Delta(1+r)}}^{3}] g_{t+1}
$$

As in Section 3.2, the dependency-ratio effect (effect 3) works in the opposite direction as in the defined-benefit case, i.e. leads to higher savings as pension benefits have to decrease after a fall in fertility. As a result, this effect intensifies the capitalthickening effect, so that individuals in the PAYG country now also experience positive long-run utility effects of a fertility decline. Moreover, because the funded country has no dependency-ratio effect, the capital-labour ratio actually rises less in this country. This means that the spillover effects turn around; this holds both for the short-run and the long run, so that in the long run, citizens in country $P$ suffer and those living in country $F$ gain from having an integrated capital market with a country that uses another pension scheme. Figure 8, however, shows that the difference between the change in $k_{t}$ in the two countries is very small, especially in the long run. This implies that these opposite spillovers are also very small. Moreover, the next section shows that these spillovers are not robust to changes in the intertemporal elasticity of substitution.

\subsection{CES utility function}

The results presented until now are based on a logarithmic utility function, which means that the intertemporal elasticity of substitution $(\sigma)$ is equal to one. In the literature, values taken for $\sigma$ range from $\frac{1}{4}$ to $\frac{1}{2}, 15$ which implies that our assumption

$\overline{15}$ Auerbach and Kotlikoff (1987), for example, assume a value of $\frac{1}{4}$. 
Fig. 9 Change in $k_{t}$

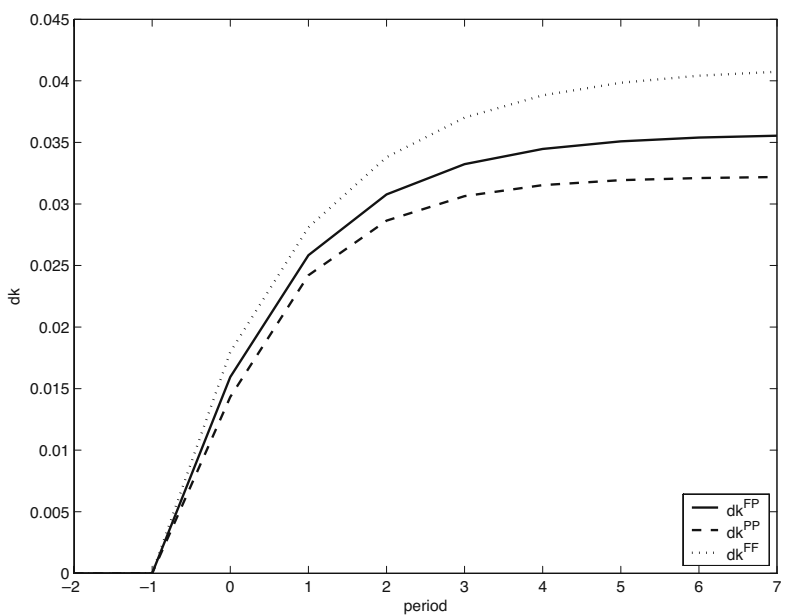

of $\sigma=1$ is probably not very realistic. Therefore, we also simulated the model for smaller values of $\sigma \cdot{ }^{16}$ If $\sigma<1$, the income effect is larger than the substitution effect, and a falling interest rate leads to higher savings. This positive effect on savings is largest in the funded country because it has the highest savings in the initial steady state. Consequently, the negative spillover effects for the funded country in case $\sigma=$ 1 will only be reinforced if $\sigma<1$. This gives the following result:

Result 2. The findings stated in Result 1 do not change if the intertemporal elasticity of substitution is smaller than one.

In the previous subsection, it was shown that, in case of a fertility shock and a fixed-contributions PAYG scheme, savings in country $P$ increased more than in country $F$ when $\sigma=1$, resulting in small positive spillover effects for the funded country. For a small enough value of $\sigma$, however, the interest rate effect of $\sigma<1$ dominates the dependency-ratio effect, so that savings in country $F$ increase more than in country $P$. This is illustrated in Fig. 9, where the change in $k_{t}$ for $\sigma=\frac{1}{4}$ is shown.

This means that the funded country experiences negative spillover effects of the PAYG scheme as in the other cases. So, we can conclude that, for smaller and probably more realistic values for the intertemporal elasticity of substitution, the long-run spillovers for the funded country are negative in all considered cases.

The main result of a fertility decline is:

Result 3. In case ageing is characterised by an unexpected decrease in fertility, for realistic values of the intertemporal elasticity of substitution the PAYG scheme causes negative spillovers to the funded country in the long run, while in the short-

${ }^{16}$ For expositional clarity, we do not show the analytical expressions for the case of a CES utility function. 
run the spillovers are positive. So the spillovers do not differ qualitatively from those in case of an increase in longevity.

\subsection{Anticipated and asymmetric shocks}

So far, we have only analysed unexpected demographic shocks. It is often argued, however, that the demographic changes that characterise population ageing are largely anticipated. Therefore, we also studied the results of an increase in longevity and a decrease in fertility that is anticipated one period before the shock actually takes place. Only the short-run effects of the shocks are slightly different in this case; the long-run results are identical to the ones presented in the previous sections. Differences are largest in case of an anticipated increase in longevity and a definedbenefits PAYG scheme. In that case, savings already adjust in the period before the shock, which leads to a rise in the capital-labour ratio at $t=0$ as a net result of effects 1 and 2 in Eqs. 10, 11 and 12. Just as with an unexpected shock, from $t=0$ on, there is a dependency-ratio effect, which negatively affects the capital-labour ratio in the next period. As a result of this, in case both countries use a PAYG system, the increase in $k_{t}$ at $t=1$ is smaller than at $t=0$. The spillover effects are not qualitatively different however.

A further robustness check is to assume asymmetric ageing, i.e. longevity or fertility may change more in one country than in the other. The model can easily be extended to allow for this. Let us consider two extreme cases: ageing only in country $F$ and ageing only in country $P$. In the former case, savings will only increase in the funded country, which obviously leads to a large capital flow from country $F$ to country $P$ and thus reinforces our results. In the latter case, savings will only increase in the PAYG country. This clearly reverses the spillover effect: Capital now flows from the ageing unfunded country to the funded country. Due to the PAYG pensions, the capital flow in this case is smaller than in the opposite one. Therefore, when both extreme cases are combined, as we did in our model, a net capital flow from country $F$ to country $P$ results.

\section{Concluding remarks}

In the coming decades, most European countries will have an ageing population. These countries differ in the degree of funding of their pension systems. On the one hand, there are countries like the UK and The Netherlands that have an extensive funded pension system. Most other countries, on the other hand, mainly rely on unfunded pensions. These differences in pension schemes engender different saving responses when the population is ageing, which leads to capital flows. This paper focuses on the question how, in case of population ageing, countries are affected by the fact that other countries use other pension systems. We find that, in the long run, a PAYG country gains from having a common capital market with a country relying on funded pensions; the main reason being that, in the funded country, savings increase more in response to ageing. A country using a funded retirement scheme, on the other hand, experiences long-run negative spillover effects from the PAYG system in the other country. The short-run spillovers, however, are opposite to the spillovers in the long run. In other words, the initial generations in the funded country gain from the fact that the other country uses a PAYG scheme, whereas these initial 
generations in the PAYG country are negatively affected by the funded system in the other country.

We have shown that our results are quite robust for modifications to the basic model used in this paper. Extensions of the analysis that we leave for future research would, for example, be to allow for endogenous labour supply, and the fact that an increase in longevity can also lengthen the working period of people. Moreover, this paper considers balanced PAYG pension systems, that is, in response to population ageing, contributions or pension benefits adjust in such a way so that the PAYG scheme does not run a deficit. Governments in funded countries, however, are mainly concerned about the negative effects of unbalanced PAYG schemes. In other words, they worry how their country will be affected when countries with PAYG schemes use government debt to cope with the costs of ageing. In the future, we also want to extend the model presented in this paper to allow for government debt. Moreover, by including monetary policy, it is also possible to analyse the spillover effects in case governments put pressure on the central bank to accommodate, so that their debt burden is reduced. This paper, however, already shows that countries with funded pensions are mostly negatively affected by the fact that other countries have PAYG pension schemes, even when the government of the PAYG country keeps its pension system balanced.

Acknowledgements We are grateful for useful comments from Lans Bovenberg, Jan Bonenkamp, Alessandra Casarico, Robert Fenge, Sweder van Wijnbergen and two anonymous referees. Furthermore, we would like to thank the participants of the IIPF Conference, Paphos, Cyprus, August 2006; the Scientific Workshop at the Caissedes Dépôts, Bordeaux, France, March 2006; the CPB seminar, The Hague, The Netherlands, September 2005; the ESPE conference, Paris, France, June 2005; the Netspar Pension Day, Tilburg, The Netherlands, June 2005; and the Economics lunch seminar, Tilburg, The Netherlands, May 2005, for valuable comments and discussions.

\section{Appendix 1: Derivation of the first-order difference equation of the capital-labour ratio}

In this appendix, we derive the first-order difference equation for the evolution of the capital-labour ratio given in Eq. 10. Linearising the capital-accumulation Eq. 8 with respect to $\pi$ around the initial steady state gives:

$$
\frac{\partial s_{t}^{P}}{\partial \pi}+v \frac{\partial\left(s_{t}^{F}+\tau_{t}^{F}\right)}{\partial \pi}=(1+v) \frac{\partial k_{t+1}}{\partial \pi}
$$

Then we derive expressions for $\frac{\partial s_{t}^{P}}{\partial \pi}$ and $\frac{\partial\left(s_{t}^{F}+\tau_{t}^{F}\right)}{\partial \pi}$, using Eqs. 6 and 7:

$$
\begin{aligned}
\frac{\partial s_{t}^{P}}{\partial \pi}= & \frac{(1+\rho)\left(w-\tau^{P}\right)}{(1+\rho+\varepsilon)^{2}} \frac{\partial \varepsilon_{t+1}}{\partial \pi}+\frac{\varepsilon}{1+\rho+\varepsilon}\left[\frac{\partial w_{t}}{\partial \pi}-\frac{\partial \tau_{t}^{P}}{\partial \pi}\right] \\
& +\frac{(1+\rho) \varepsilon z^{P}}{(1+\rho+\varepsilon)^{2}(1+r)} \frac{\partial \varepsilon_{t+1}}{\partial \pi}-\frac{(1+\rho) z^{P}}{(1+\rho+\varepsilon)(1+r)} \frac{\partial \varepsilon_{t+1}}{\partial \pi} \\
& +\frac{(1+\rho) \varepsilon z^{P}}{(1+\rho+\varepsilon)(1+r)^{2}} \frac{\partial r_{t+1}}{\partial \pi} \\
& \frac{\partial\left(s_{t}^{F}+\tau_{t}^{F}\right)}{\partial \pi}=\frac{(1+\rho) w}{(1+\rho+\varepsilon)^{2}} \frac{\partial \varepsilon_{t+1}}{\partial \pi}+\frac{\varepsilon}{1+\rho+\varepsilon} \frac{\partial w_{t}}{\partial \pi}
\end{aligned}
$$


$\frac{\partial w_{t}}{\partial \pi}$ and $\frac{\partial r_{t+1}}{\partial \pi}$ are given by:

$$
\begin{aligned}
\frac{\partial w_{t}}{\partial \pi} & =-k f^{\prime \prime}(k) \frac{\partial k_{t}}{\partial \pi} \\
\frac{\partial r_{t+1}}{\partial \pi} & =f^{\prime \prime}(k) \frac{\partial k_{t+1}}{\partial \pi}
\end{aligned}
$$

Combining Eqs. 19, 20, 21, 22 and 23 and simplifying gives:

$$
\begin{aligned}
\frac{\partial k_{t+1}}{\partial \pi}= & -\frac{\varepsilon f^{\prime \prime}(k) k}{\Psi} \frac{\partial k_{t}}{\partial \pi}-\frac{\varepsilon}{(1+v) \Psi} \frac{\partial \tau_{t}^{P}}{\partial \pi} \\
& +\left[\frac{(1+\rho)\left(w-\frac{\tau^{P}}{1+\nu}\right)}{\Psi(1+\rho+\varepsilon)}-\frac{(1+\rho)^{2} z^{P}}{(1+v) \Psi(1+\rho+\varepsilon)(1+r)}\right] \frac{\partial \varepsilon_{t+1}}{\partial \pi}
\end{aligned}
$$

with $\Psi \equiv(1+\rho+\varepsilon)-\frac{(1+\rho) \varepsilon z^{P} f^{\prime \prime}(k)}{(1+v)(1+r)^{2}}$.

Using Eqs. 2 and 9, we know that:

$$
\begin{aligned}
\frac{\partial \tau_{t}^{P}}{\partial \pi} & =z^{P} \frac{\partial \varepsilon_{t}}{\partial \pi} \\
\frac{\partial \varepsilon_{t+1}}{\partial \pi} & =h_{t+1}
\end{aligned}
$$

Substituting these last two expressions into Eq. 24, we obtain Eq. 10.

\section{Appendix 2: Conditions for a long-run increase in $\boldsymbol{k}_{\boldsymbol{t}}$}

\subsection{Longevity shock}

As explained in Section 3.1, the capital-labour ratio rises after a permanent increase in longevity as long as:

$$
\frac{z^{P}}{1+v}<\frac{(1+\rho)(1+r) w}{\varepsilon(1+\rho)(1+r)+(1+\rho)^{2}+\varepsilon(1+\rho+\varepsilon)(1+r)}
$$

In the same way, we can obtain a condition for the case where the PAYG country does not have a common capital market with a country that uses a funded system:

$$
z^{P}<\frac{(1+\rho)(1+r) w}{\varepsilon(1+\rho)(1+r)+(1+\rho)^{2}+\varepsilon(1+\rho+\varepsilon)(1+r)}
$$

The two graphs below show how the sign of these two conditions changes for different parameter values. ${ }^{17}$ For positive values on the vertical axis, the above conditions hold, and an increase in longevity leads to an increase in the capitallabour ratio. The horizontal axis shows the relative size of the lump-sum PAYG tax compared to the wage.

As can be seen in Fig. 10, condition 27 holds in the standard case as long as $\tau^{P}<$ $0.6 w$. For other parameter values, the PAYG system can be even larger. Therefore,

${ }^{17}$ The standard case is characterised by $\alpha=0.3, \varepsilon=0.94, v=1, \delta=0.7854$ and $\rho=0.3478$. See also note 10 . 
Fig. 10 Condition 27

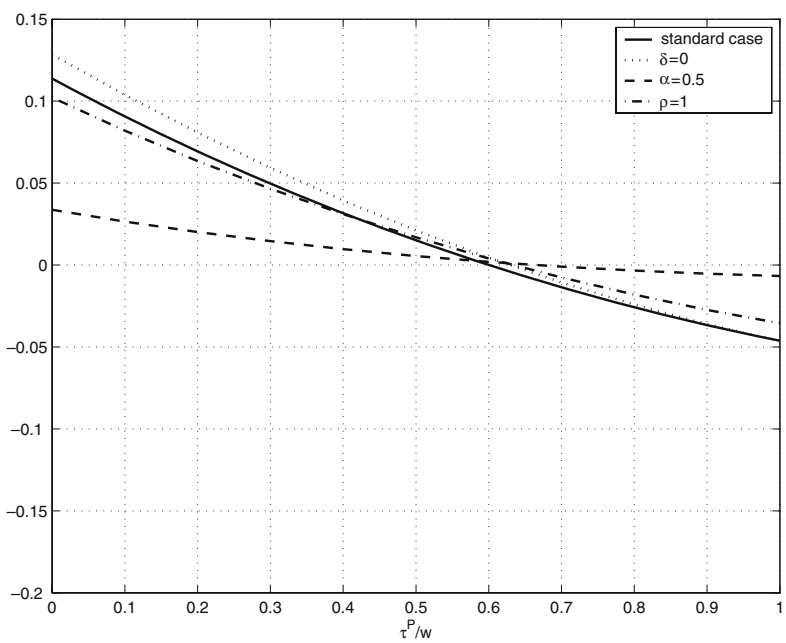

we can say that, for realistic parameter values, the capital-labour ratio increases after a rise in longevity when one country has a PAYG scheme and the other country uses a funded system.

In case both countries use a PAYG system (see Fig. 11), the capital-labour ratio only rises after a permanent increase in longevity as long as $\tau^{P}<0.28 w$. This is not an unrealistically high value for the contribution rate of the PAYG system, especially when expenditures on medical care are included, implying that the capital-labour ratio may actually fall after a rise in longevity when both countries use a PAYG scheme. This is the point Fehr et al. (2005) make. They argue that the increase in taxes needed to finance the benefits is so large that the capital-labour ratio falls after an ageing shock. Most other studies that use multi-country general equilibrium models, however, find that ageing increases the capital stock per worker; see Brooks (2003), Miles (2001), McMorrow and Röger (2004), Börsch-Supan et al. (2006), Domeij and Flodén (2006) and Attanasio et al. (2006). It appears, however, that the results of Fehr et al. (2005) are mainly driven by the fact that the effective labour supply is rising due to labour-augmenting technical progress, which more than offsets the reduction in the labour force when the economy is ageing. But it is not obvious at all whether technical progress will be able to offset the negative effects on the supply of labour. Therefore, we follow the other studies and assume that an increase in longevity results in a higher capital-labour ratio if both countries rely on PAYG pensions when we present the simulation graphs in the main text. ${ }^{18}$ The spillovers do not change qualitatively when $k_{t}^{P P}$ falls instead; the reason being that the spillovers depend on the relative change in $k_{t}^{F F}$ to $k_{t}^{P P}$. As the dependency-ratio effect is absent when both countries use funded pensions, the capital-labour ratio unambiguously increases more in that case, that is, we always have that $d k_{t}^{F F}>d k_{t}^{P P}$.

\footnotetext{
${ }^{18}$ The simulation graphs are based on the assumption that $\tau^{P}=0.2 w$. 
Fig. 11 Condition 28

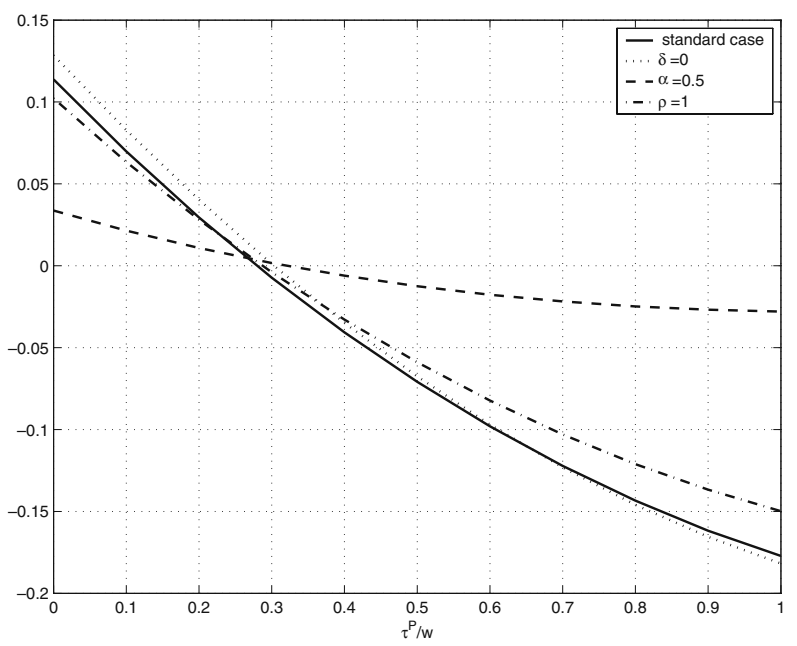

\subsection{Fertility shock}

As explained in footnote 13, the capital-labour ratio rises after a permanent decline in fertility if:

$$
\frac{z^{P}}{1+v}<(2+\rho) k,
$$

whereas this condition in case both countries have a PAYG pension scheme is equal to:

$$
z^{P}<(2+\rho) k
$$

As before, we produce graphs that show how the sign of these two conditions changes for different parameter values.

Fig. 12 Condition 29

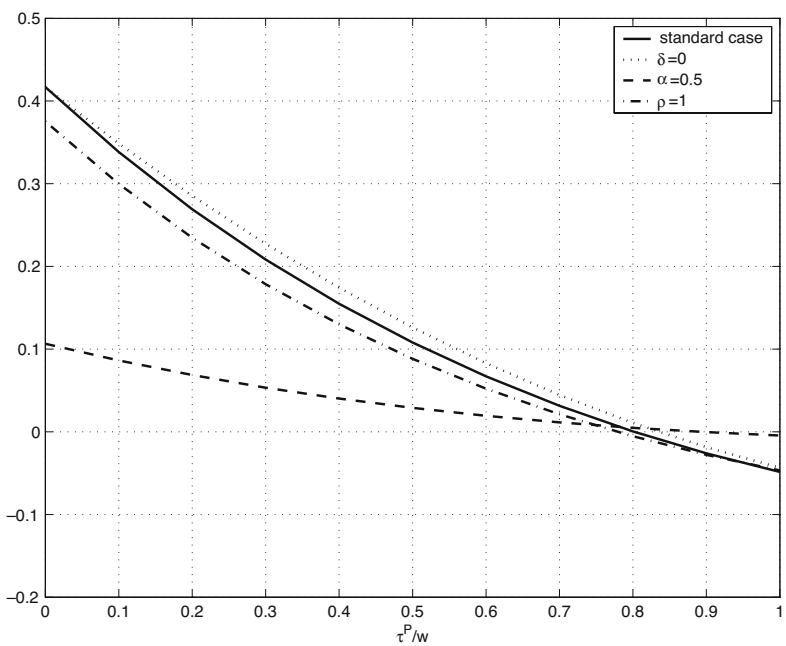


Fig. 13 Condition 30

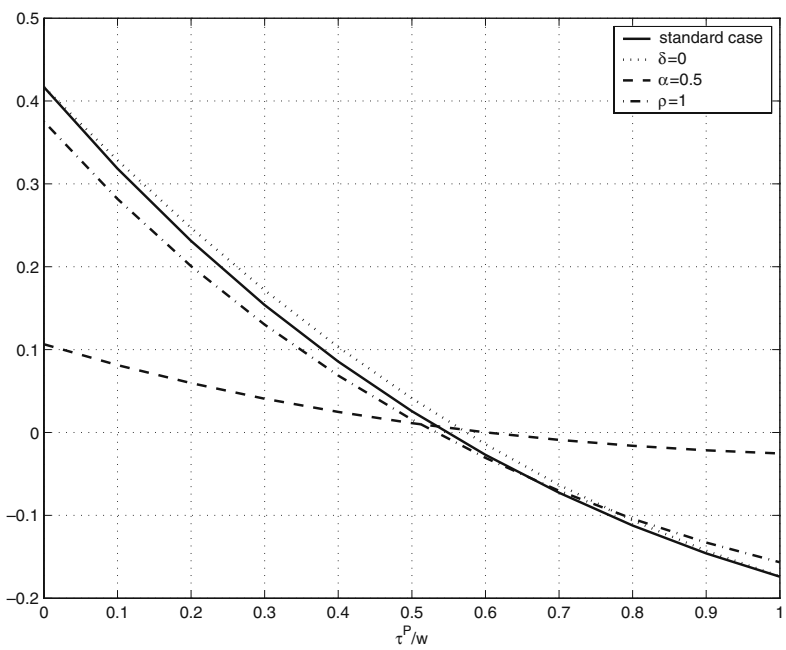

Figure 12 shows that condition 29 holds in the standard case as long as $\tau^{P}<0.8 w$, whereas we can see in Fig. 13 that condition 30 holds if $\tau^{P}<0.55 w$. This means that, in case ageing is characterised by a fall in the fertility rate, the capital-labour ratio only falls when the PAYG system is unrealistically large.

\section{Appendix 3: Effects on utility}

In this appendix, we derive the expressions for the long-run change in utility in both countries. From these equations, we can infer the relationship between the change in the capital-labour ratio and utility.

\subsection{PAYG country}

First, we derive the change in long-run utility in country $P$. Therefore, we first need to know what happens with consumption in both periods of life in the long run:

$$
\begin{gathered}
\frac{\partial c_{\infty}^{y, P}}{\partial \pi}=\frac{\partial w_{\infty}}{\partial \pi}-\frac{\partial \tau_{\infty}^{P}}{\partial \pi}-\frac{\partial s_{\infty}^{P}}{\partial \pi} \\
\frac{\partial c_{\infty}^{o, P}}{\partial \pi}=\frac{(1+r)}{\varepsilon} \frac{\partial s_{\infty}^{P}}{\partial \pi}+\frac{s^{P}}{\varepsilon} \frac{\partial r_{\infty}}{\partial \pi}-\frac{(1+r) s^{P}}{\varepsilon^{2}} \frac{\partial \varepsilon_{\infty}}{\partial \pi}+\frac{\partial z_{\infty}^{P}}{\partial \pi}
\end{gathered}
$$

The long-run change in utility is: ${ }^{19}$

$$
\frac{\partial U_{\infty}^{P}}{\partial \pi}=\frac{1}{c^{y, P}} \frac{\partial c_{\infty}^{y, P}}{\partial \pi}+\frac{\varepsilon}{1+\rho} \frac{1}{c^{o, P}} \frac{\partial c_{\infty}^{o, P}}{\partial \pi}
$$

\footnotetext{
${ }^{19}$ This equation shows the change in utility for a person living for two periods with certainty, i.e. $\varepsilon=1$. 
Using the Euler condition $\left(\frac{c^{y, P}}{c^{o, P}}=\frac{1+\rho}{1+r}\right)$, Eq. 33 can be written as:

$$
\frac{\partial U_{\infty}^{P}}{\partial \pi}=\frac{1}{c^{y, P}}\left(\frac{\partial c_{\infty}^{y, P}}{\partial \pi}+\frac{\varepsilon}{1+r} \frac{\partial c_{\infty}^{o, P}}{\partial \pi}\right)
$$

Substituting Eqs. 31 and 32 into Eq. 34 gives:

$$
\begin{aligned}
\frac{\partial U_{\infty}^{P}}{\partial \pi}= & \frac{1}{c^{y, P}}\left[\frac{\partial w_{\infty}}{\partial \pi}-\frac{\partial \tau_{\infty}^{P}}{\partial \pi}-\frac{\partial s_{\infty}^{P}}{\partial \pi}\right] \\
& +\frac{1}{c^{y, P}}\left[\frac{\varepsilon}{1+r}\left(\frac{(1+r)}{\varepsilon} \frac{\partial s_{\infty}^{P}}{\partial \pi}+\frac{s^{P}}{\varepsilon} \frac{\partial r_{\infty}}{\partial \pi}-\frac{(1+r) s^{P}}{\varepsilon^{2}} \frac{\partial \varepsilon_{\infty}}{\partial \pi}+\frac{\partial z_{\infty}^{P}}{\partial \pi}\right)\right]
\end{aligned}
$$

Using that $\frac{\partial w_{\infty}}{\partial \pi}=-k f^{\prime \prime}(k) \frac{\partial k_{\infty}}{\partial \pi}$ and $\frac{\partial r_{\infty}}{\partial \pi}=f^{\prime \prime}(k) \frac{\partial k_{\infty}}{\partial \pi}$, we can write:

$$
\frac{\partial U_{\infty}^{P}}{\partial \pi}=\frac{1}{c^{y, P}}\left[-k f^{\prime \prime}(k) \frac{\partial k_{\infty}}{\partial \pi}-\frac{\partial \tau_{\infty}^{P}}{\partial \pi}+\frac{f^{\prime \prime}(k) s^{P}}{(1+r)} \frac{\partial k_{\infty}}{\partial \pi}-\frac{s^{P}}{\varepsilon} \frac{\partial \varepsilon_{\infty}}{\partial \pi}+\frac{\varepsilon}{1+r} \frac{\partial z_{\infty}^{P}}{\partial \pi}\right]
$$

With defined benefits, it holds that $\frac{\partial \tau_{\infty}^{P}}{\partial \pi}=z^{P} \frac{\partial \varepsilon_{\infty}}{\partial \pi}$ and $\frac{\partial z_{\infty}^{P}}{\partial \pi}=0$, so that this equation can be rearranged to:

$$
\frac{\partial U_{\infty}^{P}}{\partial \pi}=\frac{f^{\prime \prime}(k)}{c^{y, P}(1+r)}\left[s^{P}-k(1+r)\right] \frac{\partial k_{\infty}}{\partial \pi}-\frac{1}{c^{y, P}}\left(z^{P}+\frac{s^{P}}{\varepsilon}\right) \frac{\partial \varepsilon_{\infty}}{\partial \pi}
$$

Dividing this expression by $\frac{\partial \varepsilon_{\infty}}{\partial \pi}$, we get an expression for the change in $U^{P}$ in the long run when longevity changes (this is Eq. 14 in the text):

$$
\frac{\partial U_{\infty}^{P}}{\partial \varepsilon_{\infty}}=\frac{f^{\prime \prime}(k)}{c^{y, P}(1+r)}\left[s^{P}-k(1+r)\right] \frac{\partial k_{\infty}}{\partial \varepsilon_{\infty}}-\frac{1}{c^{y, P}}\left(z^{P}+\frac{s^{P}}{\varepsilon}\right)
$$

The following things can be said about the terms in front of $\frac{\partial k_{\infty}}{\partial \varepsilon_{\infty}}$ :

1. $\frac{f^{\prime \prime}(k)}{c^{y, P}(1+r)}<0$ because $f^{\prime \prime}(k)<0$.

2. $s^{P}-k(1+r)<0$ because we know that $s^{P}<k(1+n)$ : Country $P$ is a capital importer in the initial steady state. And because we assumed dynamic efficiency $(r>n)$, we know that $k(1+n)<k(1+r)$. So that $s^{P}<k(1+r)$.

These two points imply that an increase in the capital-labour ratio, after an increase in longevity, has positive utility effects. There are two reasons for this result:

1. A higher capital-labour ratio leads to a lower interest rate, which is good for the country that borrows money (the PAYG country).

2. Moreover, a lower interest rate means that the economy is closer to the Golden Rule point $(r=n)$.

As the rise in the capital-labour ratio is larger in case the PAYG country has integrated capital markets with a country that uses a funded system instead of PAYG system, utility is also higher in that case.

\subsection{Funded country}

Unfortunately, it is not possible to draw such a clear conclusion for the country that uses a funded pension system. The main intuition for this is as follows. Again, we 
have that a higher capital-labour ratio is good for the funded country because a lower interest rate causes the economy to be closer to its Golden Rule point. On the other hand, a lower interest rate is bad for the funded country because it is a lender of money. This can be shown more formally as follows (using the same kind of technique used above for the PAYG country). The expressions for the long-run change in consumption and utility are given by:

$$
\begin{gathered}
\frac{\partial c_{\infty}^{y, F}}{\partial \pi}=\frac{\partial w_{\infty}}{\partial \pi}-\frac{\partial\left(s_{\infty}^{F}+\tau_{\infty}^{F}\right)}{\partial \pi} \\
\frac{\partial c_{\infty}^{o, F}}{\partial \pi}=\frac{(1+r)}{\varepsilon} \frac{\partial\left(s_{\infty}^{F}+\tau_{\infty}^{F}\right)}{\partial \pi}+\frac{\left(s^{F}+\tau^{F}\right)}{\varepsilon} \frac{\partial r_{\infty}}{\partial \pi}-\frac{(1+r)\left(s^{F}+\tau^{F}\right)}{\varepsilon^{2}} \frac{\partial \varepsilon_{\infty}}{\partial \pi} \\
\frac{\partial U_{\infty}^{F}}{\partial \pi}=\frac{1}{c^{y, F}}\left(\frac{\partial c_{\infty}^{y, F}}{\partial \pi}+\frac{\varepsilon}{1+r} \frac{\partial c_{\infty}^{o, F}}{\partial \pi}\right)
\end{gathered}
$$

Substituting the equations for consumption 39 and 40 into the equation for utility 41 , and using the same expressions for $\frac{\partial w_{\infty}}{\partial \pi}$ and $\frac{\partial r_{\infty}}{\partial \pi}$ as before, the following expression for the change in utility in country $F$ can be obtained:

$$
\frac{\partial U_{\infty}^{F}}{\partial \pi}=\frac{f^{\prime \prime}(k)}{c^{y, F}(1+r)}\left[\left(s^{F}+\tau^{F}\right)-k(1+r)\right] \frac{\partial k_{\infty}}{\partial \pi}-\frac{1}{c^{y, F}} \frac{\left(s^{F}+\tau^{F}\right)}{\varepsilon} \frac{\partial \varepsilon_{\infty}}{\partial \pi}
$$

Dividing by $\frac{\partial \varepsilon_{\infty}}{\partial \pi}$, we get (Eq. 15 in the text):

$$
\frac{\partial U_{\infty}^{F}}{\partial \varepsilon_{\infty}}=\frac{f^{\prime \prime}(k)}{c^{y, F}(1+r)}\left[\left(s^{F}+\tau^{F}\right)-k(1+r)\right] \frac{\partial k_{\infty}}{\partial \varepsilon_{\infty}}-\frac{1}{c^{y, F}} \frac{\left(s^{F}+\tau^{F}\right)}{\varepsilon},
$$

which is comparable to Eq. 38 for the PAYG country. As before, we have that the first term $\left(\frac{f^{\prime \prime}(k)}{c^{y, F}(1+r)}\right)$ is negative. But we cannot say anything about the sign of the second term $\left(\left(s^{F}+\tau^{F}\right)-k(1+r)\right)$. Firstly, we know that, in the initial steady state, country $F$ is a capital exporter, which means that $s^{F}+\tau^{F}>k(1+n)$. Secondly, it holds that $r>n$ because we assume dynamic efficiency, implying that $k(1+r)>$ $k(1+n)$. So, there are two opposing mechanisms, meaning that we do not know whether $s^{F}+\tau^{F}-k(1+r)$ will be negative or positive. The first effect reflects the fact that a lower interest rate is bad for a country that is a lender in the international capital market, the second effect is the Golden Rule effect. In case the first effect dominates the second, $s^{F}+\tau^{F}-k(1+r)$ is positive, and the whole term in front of $\frac{\partial k_{\infty}}{\partial \varepsilon_{\infty}}$ is negative, implying that an increase in the capital-labour ratio after an increase in longevity actually affects utility negatively. On the other hand, when the second effect dominates the first, we have the same result as for the PAYG country: A higher capital-labour ratio leads to a higher utility in the funded country. This is the same conclusion as in Casarico (2001). 
Fig. $14 s^{F}+\tau^{F}-k(1+r)$

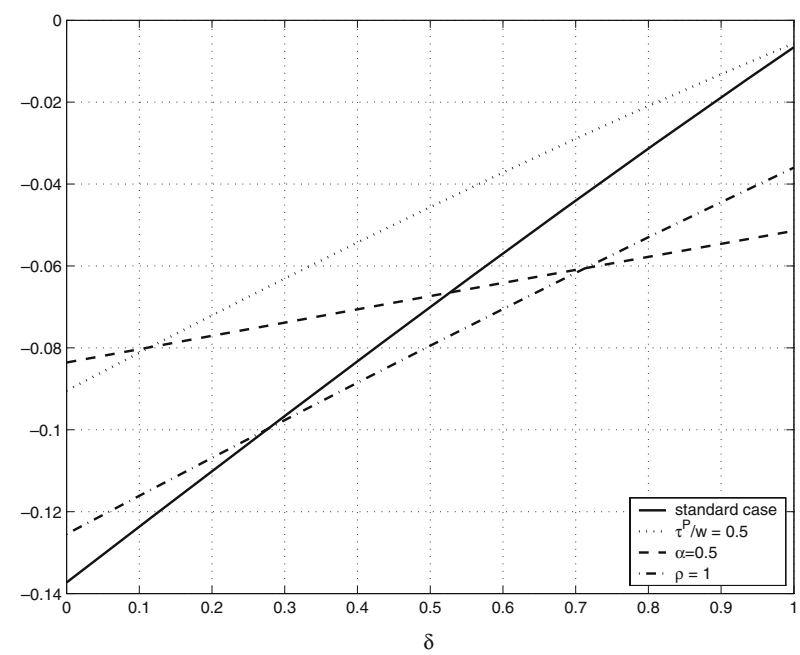

In Fig. 14, we present a graph that shows how the sign of $s^{F}+\tau^{F}-k(1+r)$ (vertical axis) changes for different parameter values. ${ }^{20}$ The horizontal axis shows the depreciation rate $(\delta)$.

This graph shows that $s^{F}+\tau^{F}-k(1+r)<0$ for various values of the parameters, which means that the Golden Rule effect dominates the interest rate effect. This in turn implies that, for realistic parameter values, a rise in the capital-labour ratio has positive utility effects in the funded country. ${ }^{21}$ As the capital-labour ratio increases more in case the funded country has a common capital market with a country that also uses a funded pension scheme, opposed to a PAYG system, utility is higher in that case.

\section{Appendix 4: Proof that $\mathrm{d} k_{t}^{P P}<\mathrm{d} k_{t}^{F F}$}

In this appendix, we prove that savings in the funded country still increase more than in the PAYG country when the PAYG scheme is characterised by fixed contributions (Section 3.2). This implies that the capital-labour ratio in the funded country increases less in case it has a common capital market with a country using a PAYG pension system.

Savings in the funded country increase more than in the PAYG country after an increase in longevity in case the following condition holds:

$$
\frac{(1+\rho)\left(w-\tau^{P}\right)}{\Psi^{P}(1+\rho+\varepsilon)}-\frac{(1+\rho)^{2} z^{P}}{\Psi^{P}(1+\rho+\varepsilon)(1+r)}+\frac{(1+\rho) \tau^{P}}{\Psi^{P}(1+r) \varepsilon}<\frac{(1+\rho) w}{\Psi^{F}(1+\rho+\varepsilon)},
$$

\footnotetext{
${ }^{20}$ In the standard case, we have the following parameter values: $\rho=0.3478, \frac{\tau^{P}}{w}=0.2, v=1, \alpha=0.3$ and $\varepsilon=0.94$.

${ }^{21}$ It is actually possible to have $s^{F}+\tau^{F}-k(1+r)>0$. This is, for example, the case when $\rho=0$ and $\delta>0.87$. A time preference rate of zero is not very realistic however. Therefore, we conclude that, for realistic parameter values, it holds that $s^{F}+\tau^{F}-k(1+r)<0$.
} 
which can be written as:

$$
\frac{\varepsilon(1+\rho)(1+r)\left(w-\tau^{P}\right)-\varepsilon(1+\rho)^{2} z^{P}+(1+\rho)(1+\rho+\varepsilon) \tau^{P}}{\Psi^{P}(1+\rho+\varepsilon)(1+r) \varepsilon}<\frac{(1+\rho) w}{\Psi^{F}(1+\rho+\varepsilon)}
$$

where:

$$
\begin{gathered}
\Psi^{P} \equiv(1+\rho+\varepsilon)-\frac{(1+\rho) \varepsilon z^{P} f^{\prime \prime}(k)}{(1+r)^{2}}>0 \\
\Psi^{F} \equiv(1+\rho+\varepsilon)>0
\end{gathered}
$$

and $\Psi^{P}>\Psi^{F}$.

Simplifying and using the fact that $z^{P}=\frac{\tau^{P}}{\varepsilon}$ gives:

$$
\frac{-\tau^{P} r}{\Psi^{P}(1+r)}<\frac{w}{\Psi^{F}}-\frac{w}{\Psi^{P}}
$$

The left-hand side is always negative, and because $\Psi^{F}<\Psi^{P}$, we know that $\frac{w}{\Psi^{F}}>\frac{w}{\Psi^{P}}$, so that the right-hand side is always positive. This implies that Eq. 48 always holds and that the positive dependency-ratio effect in case of fixed contributions is not large enough to compensate for the negative effects a PAYG system has in general, so that savings in the funded country increase more than in the PAYG country.

\section{References}

Attanasio O, Kitao S, Violante G (2006) Quantifying the effects of the demographic transition in developing economies. Adv Macroecon 6(1):1-44

Auerbach A, Kotlikoff L (1987) Dynamic fiscal policy. Cambridge University Press, Cambridge

Blundell R, MaCurdy T (1999) Labor supply: a review of alternative approaches. In: Ashenfelter O, Card D (eds) Handbook of labor economics, vol 3A. Elsevier, Amsterdam, pp 1560-1695

Börsch-Supan A, Ludwig A, Winter J (2006) Ageing, pension reform and capital flows: a multicountry simulation model. Economica 73(292):625-658

Brooks R (2003) Population aging and global capital flows in a parallel universe. IMF Staff Pap 50(2):200-221

Buiter W (1981) Time preference and international lending and borrowing in an overlappinggenerations model. J Polit Econ 89(4):769-797

Casarico A (2001) Pension systems in integrated capital markets. Topics Econ Analysis Policy 1(1):1-17

Cutler D, Poterba J, Sheiner L, Summers L (1990) An aging society: opportunity or challenge? Brookings Pap Econ Act 1:1-73

Domeij D, Flodén M (2006) Population aging and international capital flows. Int Econ Rev 47(3):1013-1032

Fehr H, Jokisch S, Kotlikoff L (2005) The developed world's demographic transition-the role of capital flows, immigration, and policy. In: Brooks R, Razin A (eds) Social security reform. Cambridge University Press, Cambridge, pp 11-43

Groezen B (2003) International spillover effects of unfunded pensions and population ageing. In: The wealth of generations: pensions and welfare from a macroeconomic perspective. CentER, Tilburg, pp 101-140

Jousten A, Legros F (2002) Pensions and savings in a monetary union: an analysis of capital flows. CEPR Discussion Paper no. 3509

Springer 
Judd K (1982) An alternative to steady-state comparisons in perfect foresight models. Econ Lett 10(1-2):55-59

McMorrow K, Röger W (2004) The economic and financial market consequences of global ageing. Springer, Berlin

Miles D (2001) Should monetary policy be different in a greyer world? In: Auerbach A, Herrmann $\mathrm{H}$ (eds) Ageing, financial markets, and monetary policy. Springer, Berlin, pp 243-276 